\title{
Inhaltsverzeichnis
}



Vorwort zur russischsprachigen Ausgabe . . . . . . . . . . . . . . . . . 15

Einleitung . . . . . . . . . . . . . . . . . . . 18

\section{Erstes Kapitel}

Naturbedingungen und Naturressourcen als ökonomische Kategorie . . . . . . . . . . 29

1. Fragen der ökonomischen Klassifikation . . . . . . . . . . . . . . . . . . . . . 29

2. Naturfaktoren und ökonomisches Wachstum . . . . . . . . . . . . . . 36

3. Zweige der primären Produktion und ihr Einfluß auf die ökonomische Entwicklung . . 43

\section{Zweites Kapitel}

Die ökonomische Bewertung von Naturressourcen . . . . . . . . . . . . . . . . 51

1. Die Rechtskonzeption . . . . . . . . . . . . . . . . . . . . . . . 51

2. Ökonomische Konzeptionen zur Bewertung von Naturressourcen . . . . . . . . . . 57

3. Differentialrente und Bewertung von Naturressourcen . . . . . . . . . . . . . . . 75

4. Naturressourcen und Nationalreichtum . . . . . . . . . . . . . . . . . . . 82

\section{Drittes Kapitel}

Die Bewertung von Naturressourcen und Methoden zur Bestimmung des Nutzeffekts von Investitionen ........................ . . . 91

1. Grundprinzipien . . . . . . . . . . . . . . . . . . . . 91

2. Allgemeine (absolute) und relative Effektivität . . . . . . . . . . . . . . . . . . 98

3. Über Effektivitätsnormative . . . . . . . . . . . . . . . . . . . . . . . . . 106

4. Die Berücksichtigung des Zeitfaktors . . . . . . . . . . . . . . . . . . . . . 112

5. Formen der Bewertung von Naturressourcen . . . . . . . . . . . . . 116

\section{Viertes Kapitel}

Die Bewertung von Bodenflächen und Berechnungen des Nutzeffekts von Investitionen . 128

1. Besonderheiten der Bewertung landwirtschaftlich genutzter Bodenflächen . . . . . . . 128

2. Die Bewertung von Bodenflächen, der für nichtlandwirtschaftliche Zwecke entzogen werden . . . . . . . . . . . . . . . . . . . . . 133

3. Die Bewertung von Bodenflächen bei der Projektierung von Wasserspeichern . . . . 143

4. Methodologische Grundlagen zur Bewertung von Bodenflächen . . . . . . . . . . . 147 


\section{Fünftes Kapitel}

Die ökonomische Bewertung von Wasserressourcen und der Nutzeffekt von Investitionen . 156

I. Die Besonderheiten von Wasserressourcen und rechtliche Fragen ihrer Nutzung . . . . 156

2. Die Wasserwirtschaft des Landes, ihre Grundfonds, die Investitionen sowie die Entwicklungstendenzen . . . . . . . . . . . . . . . . . . . . . . . . . . . 160

3. Der Nutzeffekt von Investitionen bei Investitionsbauten der Wasserwirtschaft und die ökonomische Bewertung von Wasserressourcen. . . . . . . . . . . . . . 163

4. Der Wasserpreis und Probleme der Bezahlung für die Wassernutzung . . . . . . . 173

\section{Sechstes Kapitel}

Die Effektivität von Investitionen zum Schutz der natürlichen Umwelt . . . . . . . . . 182

\section{Siebentes Kapitel}

Die Prognose von Investitionen und Naturressourcen . . . . . . . . . . . . . . 196

1. Allgemeine Prinzipien der Prognostizierung. . . . . . . . . . . . . . . . . . . 197

2. Besonderheiten der Prognose von Preisen, Normativen des Nutzeffekts und Grenzaufwendungen ....................... . . 208

\section{Achtes Kapitel}

Die ökonomische Bewertung von Naturressourcen als Faktor zur Steigerung des Nutzeffekts von Investitionen in den RGW-Mitgliedsländern. . . . . . . . . . . . . . . . . 220

1. Die ökonomische Bodenbewertung . . . . . . . . . . . . . . . . . . . . . . 222

2. Die ökonomische Bewertung von Wasserressourcen . . . . . . . . . . . . . 237

Schlußbemerkungen ...................... . . 250

Personenregister. . . . . . . . . . . . . . . . . 263

Sachregister. . . . . . . . . . . . . . . . . 265 